\title{
Pengaruh Pengalaman Kerja Dan Komunikasi Terhadap Kinerja Karyawan Di PT Wahana Semesta Abadi Setu Bekasi Jawa Barat Eka Noviyanti ${ }^{1}$, Rushadiyati ${ }^{2}$ \\ Program Studi Administrasi Bisnis Universitas Respati Indonesia email:ekkanoviyanti43@gmail.com, rus.hadiyati@gmail.com
}

\begin{abstract}
ABSTRAK
Pengalaman Kerja tidak memastikan penting tidaknya untuk mendapatkan hasil kerja yang maksimal, komunikasi sendiri adalah hal yang kuat pada saat bekerja untuk menjalin hubungan kerja yang harmonis untuk menciptakan Kinerja Karyawan yang baik dan unggul. Penelitian ini bertujuan untuk mengetahui pengaruh Pengalaman Kerja dan Komunikasi terhadap Kinerja Karyawan pada PT Wahana Semesta Abadi. Lokasi penelitian berada di lima cabang PT Wahana Semesta Abadi. Penelitian ini merupakan penelitian kuantitatif. Penarikan sampel digunakan dengan metode sampling Probabilitas dengan teknik Simple random sampling yaitu suatu metode untuk memilih sampel dimana tiap anggota populasi memiliki kesempatan yang sama untuk terpilih menjadi sampel penelitian, dengan jumlah sampel sebanyak 70 responden. Instrumen penelitian menggunakan google form. Metode analisis data pada penelitian ini menggunakan Strutural Equation Modeling - Partical Least Square (SEM - PLS) dengan menggunakan software Smart PLS versi 3.Hasil penelitian ini menunjukan bahwa terdapat : pengaruh positif dan signifikan antara pengalaman kerja terhadap kinerja karyawan, komunikasi terhadap kinerja karyawan, pengalaman kerja dan komunikasi secara bersama-sama terhadap kinerja karyawan PT Wahana Semesta Abadi. Kesimpulan terbukti bahwa ada pengaruh pengalaman kerja dan komunikasi terhadap kinerja karyawan.
\end{abstract}

Kata Kunci: Pengalaman Kerja, Komunikasi, Kinerja Karyawan

\begin{abstract}
Work experience does not ensure it is important or not to get maximum work results, communication it self is a strong thing at work to establish harmonious working relationships to create good and superior employee performance. This study aims to determine the effect of work experience and communicationon employee performance at PT Wahana Semesta Abadi.The location of this research is in five branches of PT Wahana Semesta Abadi. This research is a quanritative research. Sampling is used with the probability sampling method with the simple random sampling technique, which is a method for selecting samples where each member of the population has the same opportunity to be selected as the research sample, with a sample size of 70 respondents. The research instrument uses google form. Methodss of data analysis in this study using Strutural Equation Modeling - Partical Least Square (SEM - PLS) using Smart PLS version 3 software.The results of this study indicate that there is a positive and significant influence between work experience on employee performance, communication on employee performance, work experience and communication together on the employee performance at PT Wahana Semesta Abadi. The conclusion is proven that there is an effect of work experience and communication on employee performance.
\end{abstract}

Keywords: Work Exprerience, comumunication, Employee Performance 


\section{PENDAHULUAN}

Sesuatu kekuatan perusahaan ataupun organisasi adalah dari kinerja karyawannya itu sendiri, karena karyawan adalah suatu aset perusahaan yang merupakan bagian penting dari perusahaan. Di PT. Wahana Semesta Abadi ini dimana seperti SPBU pada umunya yaitu bergerak dalam bidang pendistribusian atau penyaluran bahan bakar minyak kepada masyarakat luas, dimana Spbu Setu Bekasi ini adalah salah satu cabang dari ke 5 (lima) cabang yang bisa untuk di teliti mengenai sumber daya manusia nya dalam kegiatan ataupun cara bekerja masing-masing cabang spbu.

Pada umumnya untuk merekrut karyawan yaitu banyak persyaratnnya, seperti pengalaman kerja sesorang untuk berjalannya suatu pekerjaan yang stabil diperusahaan baru yang akan seseorang itu bekerja, pada PT. Wahana Semesta Abadi pengalaman kerja tidak terlalu berpengaruh untuk diterima atau tidaknya, karena Spbu ini sendiri membuka lowongan setiap waktu ataupun ada pegawai yang berhenti. Dalam perekrutan sebuah perusahaan pasti selalu ada yang namanya pengalaman kerja. Suatu pembelajaran juga mencakup perubahaan yang relatif tepat dari perilaku yang diakibatkan pengalaman, pemahaman dan praktek.

Seperti yang diketahui banyak orang pengalaman kerja itu sangat penting untuk berjalannya pekerjaan kita dengan lancar dan baik kedepannya, tapi di Spbu ini sangat membuka luas

untuk yang tidak mempunyai pengalaman sama sekali, tapi tidak luput dari semua itu pastinya akan diberikan arahan kerja agar bisa bekerja dengan sesuai keahlian yang ditempatkan untuk kinerja karyawan itu sendiri.
Dalam lingkungan pekerjaan tidak lah mudah untuk memulai yang namanya bekerja pasti harus mempunyai sedikit bekal setidaknya untuk bisa bekerja dengan baik, tentu tidak hanya pengalaman kerja saja tetapi bagaimana cara beradaptasi kepada banyak orang baru agar bisa bekerja dengan ikhlas dan bahagia.

Tentunya dengan pelajar yang baru lulus bisa juga yang belum mengenal dunia kerja, harus benar-benar beradaptasi dan intropeksi diri, dan harus banyak bertanya. Karena dalam bekerja itu bukan hanya bekerja tetapi bagaimana kita menjalin suatu hubungan yang baik kepada rekan kerja maupun atasan. Maka komunikasi sangat lah penting terhadap jalannya suatu pekerjaan, kalau seseorang tidak menyukai rekan kerjanya pasti tidak akan bekerja dengan efektif dan efisien karena pasti akan memikirkan rekan kerjannya dan tidak fokus untuk bekerja, pekerjaannya tidak maksimal.

Sedangkan orang yang menjaga hubungannya terhadap rekan kerjanya itu lebih maksimal kerjanya karena merasa nyaman dengan rekan kerjannya. Komunikasi sangat penting untuk berjalannya pekerjaan dengan maksimal. Pada proses interaksi, komunikasi telah menjadi bagian yang tidak dapat terpisahkan dari kehidupan sehari-hari, yaitu suatu proses interaksi antara dua orang atau lebih untuk tujuan tertentu.

Seseorang akan sukses apabila mempunyai keahlian dalam komunikasi yang baik dalam meningkatkan kinerja dan produktivitasnya. Mampu bekerja dengan baik bila mempunyai hubungan yang baik.

Pada suatu perusahaan harus mempunyai karyawan yang menjaga hubungan baiknya dengan komunikasi karena dengan semua karyawan berhubungan baik akan mencapai suatu tujuan perusahaan 
itu sendiri tanpa saling menjatuhkan satu sama lain karyawan.

Kegagalan dalam mengelola sdm perusahaan maka akan timbul dampak terhadap kinerja karyawannya. Tak dipungkiri bahwa semakin hari jumlah karyawan atau sumber daya manusia semakin banyak, namun belum tentu semua merupakan kinerja yang berkualitas sesuai kualifikasi atau kriteria pada perusahaan. Perusahaan memerlukan kinerja karyawannya yang baik, bila tidak tercapainya suatu sumber daya manusia yang sesuai maka tidak akan tercapai tujuan perusahaan itu sendiri.

Pandangan hidup dan sikap mental yang demikian, akan mendorong manusia untuk tidak merasa cepat puas akan tetapi harus lebih mampu dalam mengembangkan diri dan meningkatkan kinerjanya. Oleh

\section{PENGaLAMAN KERJA}

Menurut Marwansyah (2014: 135) dalam (Vicki Anggraeni Purwanto \& Agus Hermani, n.d.) menyatakan bahwa pengalaman kerja adalah suatu pengetahuan, keterampilan, dan kemampuan yang dimiliki pegawai untuk mengemban tanggung jawab dari pekerjaan sebelumnya, indikator dari pengalam kerja adalah: pengetahuan, keterampilan, kemampuan dan tanggungjawab.

Menurut Malayu S.P Hasibuan (2016: 55) dalam menyatakan bahwa orang yang berpengalaman merupakan calon karyawan yang telah siap pakai. Pengalaman kerja seorang pelamar hendaknya mendapat pertimbangan utama dalam proses seleksi.

Pengalaman kerja adalah suatu ukuruan tentang lama waktu atau masa kerjanya yang telah ditempuh seseorang dalam memahami tugas-tugas suatu pekerjaan dan telah melaksanakannya dengan baik. Menurut Foster dan Bill (2001) menyatakan bahwa ada beberapa hal yang menentukan berpengalaman tidaknya seseorang karyawan karena itu didalam usaha mencapai yang diinginkan hendaknya terlebih dahulu harus ada upaya yang bersifat pengorbanan, sehingga dalam arti yang sederhana dan teknis pengertian kinerja karyawan adalah dapat ditafsirkan bahwa kinerja karyawan erat kaitannya dengan hasil pekerjaan seseorang dalam suatu organisasi, hasil pekerjaan tersebut dapat menyangkut kualitas, kuantitas dan ketetapan waktu.

Dengan adanya peningkatan kinerja pada suatu perusahaan yang dilandaskan dengan keahlian dan hubungan baik terhadap karyawan lain. Pada perusahaan dengan maksimal agar tercapainya suatu tujuan perusahaan dalam melancarkan sistem kerja yang efektif.

yang sekaligus sebagai dimensi dan indikator pengalaman kerja yaitu :

1. Lama waktu atau masa kerja :

a. Ukuran tentang lama waktu atau masa kerja yang telah ditempuh seseorang dapat memahami tugas-tugas suatu pekerjaan dan telah melaksanakan dengan baik.

2. Tingkat pengetahuan dan keterampilan yang dimiliki :

a. Pengetahuan merujuk pada konsep, prinsip, prosedur, kebijakan atau informasi lain yang dibutuhkan oleh karyawan. Pengetahuan juga mencakup kemampuan untuk memahami dan menerapkan informasi pada tanggung jawab pekerjaan.

b. Keterampilan merujuk informasi pada tanggung jawab pekerjaan.

3. Penguasaan terhadap pekerjaan dan peralatan :

a. Tingkat penguasaan seseorang dalam pelaksanakaan aspek-aspek Teknik pekerjaan. 
b. Menyelesaikan pekerjaan sesuai dengan tepat waktu yang telah ditentukan.

Berdasarkan pengertian dari para pakar dapat disimpulkan bahwa: pengalaman kerja adalah suatu proses pembelajaran untuk menjadi lebih baik, agar biasa mendeteksi kesalahan-kesalahan pekerjaan yang terjadi.yang indikatornya adalah berdasarkan sikap, kemampuan dan keterampilan.

\section{KOMUNIKASI}

Menurut Syamsudin dan Firmansyah (2016: 31) menyatakan bahwa komunikasi adalah proses pengiriman dan penerimaan informasi atau pesan antara dua orang atau lebih dengan cara efektif, sehingga pesan yang dimaksud dapat dimengerti.

Menurut Liliweri (2014: 359) menyatakan bahwa komunikasi merupakan rangkaian proses pengalihan informasi dari satu orang kepada orang lain dengan maksud tertentu.

dilakukan oleh langsung karyawan untuk memberikan pelayanan dengan cepat dan tanggap.

Dimensi yang dikekemukakan oleh Pace dan Faules (2015: 184-205) sebagai berikut :

1. Komunikasi ke Bawah

2. Komunikasi ke Atas

3. Komunikasi Horizontal

4. Komunikasi Lintas Saluran

5. Komunikasi Informal

\section{KINERJA KARYAWAN}

Menurut Mangkunegara (2016: 67) menyatakan bahwa kinerja adalah hasil kerja secara kualitas dan kuantitas yang dicapai oleh seorang pegawai dalam melaksanakan tugasnya sesuai dengan tanggungjawab yang diberikan kepadanya.
Menurut Edison (2016: 190) menyatakan bahwa kinerja adalah hasil dari suatu proses yang mengacu dan diukur selama periode waktu tertentu berdasarkan ketentuan atau kesepakatan yang telah ditetapkan sebelumnya.

Dimensi dan indikator kinerja yang digunakan dalam penelitian ini mengadaptasi teori yang diutarakan oleh mangkunegara (2011: 61) yang dibagi kedalam lima dimensi dan sepuluh indikator, yaitu:

1. Kuatitas

2. Kualitas

3. Kerjasama

4. Tanggung jawab

5. Inisiatif

\section{METODOLOGI PENELITIAN}

Penelitian ini termasuk jenis penelitian kuantitatif. Metode analisis data menggunakan analiasi Structural Equation Modeling-Partial Least Square (SEM-PLS) software Smart PLS versi 3. Populasi dalam penelitian ini adalah karyawan PT Wahana Semesta Abadi Setu Bekasi Jawa Barat yang menurut data observasi pra penelitian berjumlah 70 orang Populasi bersifat heterogen sehingga teknis pengambilan sampel adalah Non Probability Sampling dengan metode Accidental Sampling, dengan jumlah sampel sebanyak 70 responden. Adapun tahap-tahap pengujiannya adalah uji validitas, uji reliabilitas, inner model meliputi convergent validity, discrimnant validity, composite validity, cronbach's alpha, outer model meliputi uji path coefficient dan uji hipotesis.

HASIL

Berdasarkan penelitian yang telah dilakukan maka didapat hasil Uji Validitas Pengalaman Kerja $\left(\mathbf{X}_{1}\right)$, Komunikasi $\left(\mathbf{X}_{2}\right)$ dan Kinerja Karyawan (Y) pada Tabel 1.

Tabel 1.

Uji Validitas Pengalaman Kerja ( $\left.\mathbf{X}_{1}\right)$, Komunikasi $\left(\mathbf{X}_{2}\right)$ 
Jurnal Administrasi Dan Manajemen

http://ejournal.urindo.ac.id/index.php/administrasimanajemen/index
E-ISSN 2623-1719

P-ISSN 1693-6876

\section{Dan Kinerja Karyawan (Y)}

Uji Validitas

Pengalaman Kerja ( $\left.\mathrm{X}_{1}\right)$

\begin{tabular}{cccc}
\hline Indikator & $\begin{array}{c}\mathrm{r}- \\
\text { hitung }\end{array}$ & $\begin{array}{c}\mathrm{r}- \\
\text { tabel }\end{array}$ & Keterangan \\
\hline $\mathrm{X}_{1.1}$ & 0,819 & 0,195 & Valid \\
$\mathrm{X}_{1} .2$ & 0,627 & 0,195 & Valid \\
$\mathrm{X}_{1} .3$ & 0,801 & 0,195 & Valid \\
$\mathrm{X}_{1} .4$ & 0,675 & 0,195 & Valid \\
$\mathrm{X}_{1} .5$ & 0,840 & 0,195 & Valid \\
$\mathrm{X}_{1} .6$ & 0,883 & 0,195 & Valid \\
\hline
\end{tabular}

\section{Uji Validitas}

Komunikasi $\left(\mathbf{X}_{2}\right)$

\begin{tabular}{cccc}
\hline Indikator & $\begin{array}{c}\mathrm{r}- \\
\text { hitung }\end{array}$ & $\begin{array}{c}\mathrm{r}- \\
\text { tabel }\end{array}$ & Keterangan \\
\hline $\mathrm{X}_{2} .1$ & 0,832 & 0,195 & Valid \\
$\mathrm{X}_{2} .2$ & 0,803 & 0,195 & Valid \\
$\mathrm{X}_{2} .3$ & 0,714 & 0,195 & Valid \\
$\mathrm{X}_{2} .4$ & 0,715 & 0,195 & Valid \\
$\mathrm{X}_{2} .5$ & 0,789 & 0,195 & Valid \\
$\mathrm{X}_{2} .6$ & 0,728 & 0,195 & Valid \\
$\mathrm{X}_{2} .7$ & 0,565 & 0,195 & Valid \\
$\mathrm{X}_{2} .8$ & 0,637 & 0,195 & Valid \\
$\mathrm{X}_{2} .9$ & 0,874 & 0,195 & Valid \\
$\mathrm{X}_{2} .10$ & 0,805 & 0,195 & Valid \\
$\mathrm{X}_{2.11}$ & 0,544 & 0,195 & Valid \\
$\mathrm{X}_{2} .12$ & 0,742 & 0,195 & Valid \\
\hline
\end{tabular}


Uji Validitas

Kinerja Karyawan (Y)

\begin{tabular}{cccc}
\hline Indikator & $\begin{array}{c}\text { r- } \\
\text { hitung }\end{array}$ & $\begin{array}{c}\text { r- } \\
\text { tabel }\end{array}$ & Keterangan \\
\hline Y1 & 0,676 & 0,195 & Valid \\
Y2 & 0,643 & 0,195 & Valid \\
Y3 & 0,855 & 0,195 & Valid \\
Y4 & 0,853 & 0,195 & Valid \\
Y5 & 0,861 & 0,195 & Valid \\
Y6 & 0,865 & 0,195 & Valid \\
Y7 & 0,736 & 0,195 & Valid \\
Y8 & 0,858 & 0,195 & Valid \\
Y9 & 0,588 & 0,195 & Valid \\
\hline
\end{tabular}

\section{Uji Reabilitas}

\begin{tabular}{lccc}
\multicolumn{4}{c}{ Hasil Uji Reabilitas } \\
\hline \multicolumn{1}{c}{ Variabel } & $\begin{array}{c}\text { Cronbach } \\
\text { Alpha }\end{array}$ & $\begin{array}{c}\text { Nilai } \\
\text { Kritis }\end{array}$ & Keterangan \\
\hline $\begin{array}{l}\text { Pengalaman } \\
\text { Kerja }\end{array}$ & 0,868 & 0,600 & Reliabel \\
$\begin{array}{l}\text { Komunikasi } \\
\text { Kinerja }\end{array}$ & 0,921 & 0,600 & Reliabel \\
Karyawan & 0,915 & 0,600 & Reliabel \\
\hline
\end{tabular}

\section{Inner Model}

\begin{tabular}{|c|c|c|}
\hline \multicolumn{3}{|c|}{ Outer loading } \\
\hline Variabel & Indikator & Outerloading \\
\hline \multirow{6}{*}{$\begin{array}{c}\text { Pengalaman Kerja } \\
\left(\mathbf{X}_{1}\right)\end{array}$} & $\mathrm{X}_{1.1}$ & 0.819 \\
\hline & $\mathrm{X}_{1.2}$ & 0.627 \\
\hline & $\mathbf{X}_{1.3} .3$ & 0.801 \\
\hline & $X_{1.4}$ & 0.675 \\
\hline & $X_{1.5}$ & 0.840 \\
\hline & $X_{1.6}$ & $\mathbf{0 , 8 8 3}$ \\
\hline \multirow[t]{6}{*}{ Komunikasi $\left(\mathbf{X}_{2}\right)$} & $X_{2.1}$ & 0.832 \\
\hline & $X_{2.2}$ & 0.803 \\
\hline & $X_{2.3}$ & 0.714 \\
\hline & $X_{2.4}$ & 0.715 \\
\hline & $X_{2.5}$ & 0.789 \\
\hline & $X_{2.6}$ & 0,728 \\
\hline
\end{tabular}


Jurnal Administrasi Dan Manajemen

http://ejournal.urindo.ac.id/index.php/administrasimanajemen/index

\begin{tabular}{cc}
$X_{2.7}$ & $\mathbf{0 , 5 6 5}$ \\
$X_{2.8}$ & $\mathbf{0 , 6 3 7}$ \\
$X_{2.9}$ & $\mathbf{0 , 8 7 4}$ \\
$X_{2.10}$ & $\mathbf{0 , 8 0 5}$ \\
$X_{2.11}$ & $\mathbf{0 , 5 4 4}$ \\
X2.12 $_{2.12}$ & $\mathbf{0 , 7 4 2}$ \\
Y1 & $\mathbf{0 . 6 7 6}$ \\
& \\
Y2 & $\mathbf{0 . 6 4 3}$ \\
Y3 & $\mathbf{0 . 8 5 5}$ \\
Y4 & $\mathbf{0 . 8 5 3}$ \\
Y5 & $\mathbf{0 . 8 6 1}$ \\
Y6 & $\mathbf{0 , 8 6 5}$ \\
Y7 & $\mathbf{0 , 7 3 6}$ \\
Y8 & $\mathbf{0 , 8 5 8}$ \\
Y9 & $\mathbf{0 , 5 8 8}$ \\
\hline
\end{tabular}

Nilai AVE

\begin{tabular}{ll}
\hline \multicolumn{1}{c}{ Variabel } & AVE \\
\hline Pengalaman Kerja $\left(\mathrm{X}_{1}\right)$ & $\mathbf{0 . 6 0 8}$ \\
Komunikasi $\left(\mathrm{X}_{2}\right)$ & $\mathbf{0 . 5 4 3}$ \\
Kinerja Karyawan $(\mathrm{Y})$ & $\mathbf{0 . 6 0 5}$ \\
\hline
\end{tabular}

\section{Composite Reability}

\begin{tabular}{lc}
\multicolumn{2}{c}{ Nilai Composite Reability } \\
\hline \multicolumn{1}{c}{ Variabel } & Composite Reliability \\
\hline Pengalaman Kerja $\left(\mathrm{X}_{1}\right)$ & 0.902 \\
Komunikasi $\left(\mathrm{X}_{2}\right)$ & 0.933 \\
Kinerja Karyawan $(\mathrm{Y})$ & 0.931 \\
\hline
\end{tabular}

\section{Cronbach's Alpha}

Nilai Cronbach's Alpha

\begin{tabular}{lc}
\hline \multicolumn{1}{c}{ Variabel } & Cronbach's Alpha \\
\hline Pengalaman Kerja $\left(\mathrm{X}_{1}\right)$ & 0.868 \\
Komunikasi $\left(\mathrm{X}_{2}\right)$ & 0.921 \\
Kinerja Karyawan $(\mathrm{Y})$ & 0.915 \\
\hline
\end{tabular}




\section{Outer Model}

Uji Path Coefficient

\begin{tabular}{lc}
\multicolumn{2}{c}{ R-Square } \\
\hline \multicolumn{1}{c}{ Nilai $\boldsymbol{R}$-Square Variabel } & Nilai $\boldsymbol{R}$-Square \\
\hline Komunikasi $\left(\mathrm{X}_{2}\right)$ & 0.904 \\
Kinerja Karyawan $(\mathrm{Y})$ & 0.746 \\
\hline
\end{tabular}

\section{Uji Hipotesis}

\begin{tabular}{|c|c|c|c|c|}
\hline \multicolumn{5}{|c|}{ Path Coefficient } \\
\hline Pengaruh & $\begin{array}{c}\text { Original } \\
\text { Sample }\end{array}$ & T-Statistic & P.Value & Hasil \\
\hline $\begin{array}{l}\text { Pengalaman Kerja => } \\
\text { Kinerja Karyawan }\end{array}$ & 0,573 & 6.747 & 0.000 & Diterima \\
\hline $\begin{array}{l}\text { Komunikasi => Kinerja } \\
\text { Karyawan }\end{array}$ & 0,411 & 4.679 & 0.000 & Diterima \\
\hline $\begin{array}{l}\text { Pengalaman Kerja => } \\
\text { Komunikasi }\end{array}$ & 0,864 & 26.613 & 0.000 & Diterima \\
\hline
\end{tabular}

\section{PEMBAHASAN}

\section{Pengaruh Pengalaman Kerja terhadap Kinerja Karyawan}

Hipotesis pertama dapat diketahui bahwa variabel pengalaman kerja berpengaruh positif dan signifikan terhadap kinerja karyawan yang ditunjukkan dengan nilai Original Sampel 0.573 dan T Statistic 6.747 > $1.96 \mathrm{~T}$ table dan T-Value $=0.000(<0.05)$. Hasil hipotesis menunjukkan bahwa pengalaman kerja berpengaruh positif dan signifikan terhadap kinerja karyawan terbukti kebenarannya atau diterima

\section{Pengaruh Pengalaman Kerja terhadap Komunikasi}

Hipotesis kedua dapat diketahui bahwa variabel pengalaman kerja berpengaruh positif dan signifikan terhadap komunikasi yang ditunjukkan dengan nilai Original Sample 0.864 dan T Statistic 26.613> 1.96 T-table dan T-Value $=0.000(<0.05)$. Hasil hipotesis menunjukkan bahwa pengalaman kerja berpengaruh positif dan signifikan terhadap kominikasi kerja terbukti kebenarannya atau $\mathrm{H} 2$ diterima

\section{Pengaruh Komunikasi terhadap Kinerja Karyawan}

Hipotesis ketiga dapat diketahui bahwa variabel komunikasi berpengaruh positif dan signifikan terhadap kinerja karyawan yang ditunjukkan dengan nilai Original Sample 0.411 T-Statistic 4.679> 1.96 T-Table dan T-Value $=0.000 \quad(<0.05)$. Hasil hipotesis menyatakan bahwa komunikasi berpengaruh positif dan signifikan terhadap kinerja karyawan terbukti kebenarannya atau $\mathrm{H} 3$ diterima.

\section{SIMPULAN DAN SARAN}

\section{Kesimpulan}

1. Hasil analisis data menyimpulkan bahwa pengalaman kerja berpengaruh positif dan 
signifikan terhadap kinerja karyawan. Hal ini berarti jika pengalaman kerja baik maka akan mempengaruhi peningkatan kinerja karyawan. Begitu juga sebaliknya jika pengalaman kerja nya buruk maka akan mempengaruhi penurunan kinerja karyawan.

2. Hasil analisis data menunjukkan bahwa pengalaman kerja berpengaruh positif dan signifikan secara langsung terhadap komunikasi. Hasil dari penelitian tersebut dapat disimpulkan bahwa pengalaman kerja sangat penting karena pengalaman kerja mempunyai pengetahuan dan mudah untuk menjalin komunikasi dengan baik, dengan begitu jika pengalaman kerja nya tidak baik maka komunikasi yang dimiliki tidak akan terjalin harmonis sesama karyawan.

3. Hasil analisis data menunjukkan bahwa komunikasi berpengaruh positif dan signifikan secara langsung terhadap kinerja karyawan. Hasil penelitian tersebut dapat

disimpulkan bahwa dengan meningkatkan komunikasi dengan baik dalam bekerja maka

\section{DAFTAR PUSTAKA}

1. Adolfina, W. R. (2018). Pengaruh Pengalaman Kerja dan Pelatihan Kerja Terhadap Kinerja Karyawan PT. Telkom Indonesia Cabang Manado.

2. Agung, D. (2013). Bab II Kajian Putaka, Kerangka Pemikiran dan Hipotesis. 10-40.

3. Albertus, W. B. (2018). Pengaruh Komunikasi dan Pelatihan Terhadap Kinerja Karyawan. 86-96.

4. Ali. (2014). Bab II Landasan Teori. Jurnal, 11-26.

5. Arianto, D. A. (2013). Pengaruh Kedisiplinan, Lingkungan Kerja, dan Budaya Kerja Terhadap Kinerja Tenaga Pegawai. Ekonomi, 191-200.

6. Arikunto, S. (2010). Prosedur Penelitian Suatu pendekatan Praktek. Jakarta: Rineka Cipta. kinerja karyawan pun akan meningkat. Sebaliknya, jika komunikasi yang buruk akan mempengaruhi kinerja karyawan yang tidak baik atau meningkat.

\section{SARAN}

1) Hendaknya PT Wahana Semesta Abadi menerima karyawan dengan mempunyai kemampuan yang baik atau pengalaman kerja sebelumnya, dengan menyeleksi karyawan dengan baik.

2) Hendaknya PT Wahana Semesta Abadi membuat lingkungan kerja yang baik dan harmonis untuk menjalin suatu komunikasi yang baik sesama karyawan yang lainnya.

3) Hendaknya PT Wahana Semesta Abadi membuat karyawan termotivasi kerja yang akan meningkatkan kerjanya, untuk menghasilkan kerja yang maksimal dan baik. Dengan kuantitas dan kualitas yang ingin dicapai.

7. Ariska, D. (2016). Pengaruh Motivasi dan Disiplin Terhadap Kinerja. Ekonomi dan Bisnis, 6-22.

8. Ella Jauvani, S. d. (2010). Manajemen Sumber Daya Manusia untuk Perusahaan dari Teori ke Praktik. Jakarta: PT. Raja Grafindo.

9. Fajar. (2009). Landasan Teori. Jurnal, 22-23.

10. Foster, B. (2016). Pembinaan Untuk Peningkatan Kinerja Karyawan. Jakarta: PPM.

11. Hamid, F. S. (2009). Identifikasi Kompetensi Karyawan yang Mempengaruhi Pencapaian Kinerja Bidang Produksi Di PT. Industri Sadang Nusantara (Persero). Management, 1-40.

12. Hasibuan, M. (2011). Manajemen Sumber Daya Manusia Edisi Kedua. Jakarta: Bumi Aksara. 
13. Hermana, V. A. (2017). Pengaruh Pengalaman Kerja dan Disiplin Kerja Terhadap Kinerja Karyawan CV. Bintang Utama Semarang Bagian Body Repair. 1-10.

14. Hermiyanty, B. A. (2017). Tinjauan Pustaka. Jurnal, 1-58.

15. Kurniawan, B. (2018). Pengaruh Disiplin Kerja dan Motivasi Terhadap Kinerja. Ekonomi dan Bisnis, 11-33.

16. Lakoy, A. (2015). Pengaruh Komunikasi, Kerjasama Kelompok, dan Kreativitas Terhadap Kinerj karyawan Pada Kinerja Karyawan pada Hotel Aryaduta Manado. EMBA, 981-991.

17. Mangkunegara, P. A. (2012). Manajemen Sumber Daya Manusia Perusahaan. Bandung: Remaja Rosdakarya.

18. Manullang. (2016). Dasar-dasar Manajemen. Yogyakarta: Gadjah Mada University.
22. Robbins, S. d. (2016). Perilaku Organisasi. Jakarta: PT. Indeks Kelompok Gramedia.

23. Rosidah, A. T. (2013). Manajemen Sumber Daya Manusia Knsep, Teori dan Pengembangan dalam Konteks Organisasi Publik. Yogyakarta: Graha Ilmu.

24. Sagala, R. d. (2016). Landasan Teori. 1-17.

25. Sugiyono. (2019). Matode Penelitian Kuantitatif Kualitatif. Bandung: Alfabeta.

26. Sutrisno, E. (2011). Manajemen Sumber Daya Manusia. Jakarta: Kencana Predana Media Group.

27. Veitzal, R. (2017). Manajemen Sumber Daya Manusia Untuk Perusahaan. Jakarta: Muria Kencana. 28. Wibowo. (2010). Manajemen Kinerja. Jakarta: Rajawali Pers.

19. Muhammad, A. (2016). Komunikasi Organisasi. Jakarta: Bumi Aksara.

20. Pamulang. (2018). Disrupsi Bisnis. Bisnis, 172.

21. Robbins. (2014). Bab 2 Landasan Teori. Manajemen, 15-34. 